\title{
La España "cóncava" de Ramón Gaya
}

\author{
Elena Trapanese
}

${ }^{66} \mathrm{~S}$ oy poco partidario de autorretratos, por creerlos imposibles. Incluso los de Rembrandt, tan magníficos, claro está, no son sino pretexto pictórico, motivo plástico puro, con mucha pintura y [...] poco retrato; me limitaré, pues, a señalar aquí la fecha y el lugar de mi nacimiento (1910, Murcia) y muy poco más, ya que todo el resto me parece un material demasiado móvil aún. Mi propia pintura, a lo largo de cuarenta años de trabajo, quiero considerarla sólo como una proposición, como un continuado boceto provisional".

Con estas palabras el pintor murciano Ramón Gaya (1910-2005) se presentaba en un texto titulado Autorretrato y escrito con motivo de la exposición y presentación de su libro El sentimiento de la pintura, en la Galería Mayer de Madrid en abril de 1960. Ramón Gaya fue, además de pintor, excelente escritor y poeta y perteneció al grupo, desafortunadamente tan numeroso, de exiliados españoles, quienes habían participado y creído en los ideales republicanos. No es baladí, desde este punto de vista, que el pintor murciano fuera uno de los jóvenes pintores, junto a Eduardo Vicente y Juan Bonafé, encargados de realizar las reproducciones de las obras maestras del Prado (se trataba de obras de las máximas figuras de la pintura española: Sánchez Coello, Ribera, Zurbarán, Murillo, además de Goya, Velázquez y El Greco) para el museo ambulante (el "Museo del Pueblo") de las Misiones Pedagógicas. Se trató, como es sabido, de un proyecto cuyo principal artífice fue Manuel Bartolomé Cossío y que, pese a tener sus raíces en el proyecto institucionista de finales del siglo XIX (me refiero a los ideales de la Institución Libre de Enseñanza), pudo realizarse sólo durante la II República, entre 1931 y 1936. Se buscó a jóvenes misioneros que estuvieran dispuestos a ir a las aldeas más aisladas del país, para que los campesinos pudieran disfrutar de la cultura en todas sus manifestaciones: música, teatro, cine, pintura, literatura. Sabido es que Cossío era un gran aficionado al arte y que creía que el arte tenía un importante papel educativo: se crearon 
un Coro y un Teatro del pueblo, y había un servicio de cinematógrafo y de gramófono, además de un servicio de biblioteca. Al llegar a los pueblos, los misioneros leían un texto escrito por Bartolomé Cossío:

Somos una escuela ambulante que quiere ir de pueblo en pueblo. Pero una escuela donde no hay libros de matrícula, donde no hay que aprender con lágrimas, donde no se pondrá a nadie de rodillas como en otro tiempo [...]

[...] Porque el gobierno de la República que nos envía, nos ha dicho que vengamos, ante todo, a las aldeas, a las más pobres, a las más escondidas y abandonadas, y que vengamos a enseñaros algo, algo que no sabéis por estar siempre tan solos y tan lejos de donde otros lo aprenden, y porque nadie hasta ahora ha venido a enseñároslo; pero que vengamos también, y lo primero, a divertiros. ${ }^{1}$

La idea de crear el Museo del Pueblo (nombre que aparece en el primer cartel que anunciaba al Museo, creado por el mismo Ramón Gaya) estuvo desde el principio en el proyecto de Cossío, quien escribió:

[...] el "Museo del Pueblo" va dirigido a todas aquellas gentes humildes, que viven en las aldeas más apartadas, que no han salido de ellas o han salido sólo a las cabezas de partido, donde no hay Museos; que si han visto alguna estampa, no han visto nunca verdaderos cuadros; no conocen ninguna pintura de los grandes artistas. Quisieran las Misiones poder llevar este Museo a las aldeas más pobres, más lejanas y escondidas, como hasta ahora vienen haciendo con las demás cosas, porque para esos pueblos son principalmente las Misiones, para los desheredados. $^{2}$

La primera visión de España que Gaya construye y tiene en su juventud es, sin duda, la idea de una España republicana, de una España que no puede existir sin el pueblo. Quiero decir que las Misiones Pedagógicas no sólo tuvieron un eco en los pueblos, en las aldeas, sino que en los mismos misioneros. En palabras de Rafael Dieste, ${ }^{3}$ quien también participó en este magnífico

${ }^{1}$ Manuel Bartolomé Cossío, Una antología pedagógica. Selección de textos, presentación y bibliografía de Jaume Carbonell Sebarroja. Madrid, Ministerio de Educación y Ciencia, 1985, p. 25.

${ }^{2}$ M. B. Cossío, "Significación del Museo", en Las Misiones Pedagógicas 1931-1936. Madrid, Sociedad Estatal de Conmemoraciones Culturales/Residencia de Estudiantes, 2006, p. 363.

${ }^{3}$ El escritor Rafael Dieste (Rianxo, 1899-Santiago de Compostela, 1981) fue miembro 
proyecto: "después de haber sido misionero, difícilmente se podría ser marrullero en política, ficticio o pedante en arte, descuidado en asuntos de ética profesional". ${ }^{4}$ En un espléndido texto de 1937, titulado España, toreadores, Picasso (que se refiere a la frase pronunciada por un concierge de un hostal parisino al saber que Gaya era español), el pintor recuerda:

Yo mismo, encomendado durante años de una tarea de divulgación cultural entre las gentes populares, he podido recorrer pueblo a pueblo, palmo a palmo casi toda España, y comprobar que un lienzo de Goya venía a ser para esas gentes virginales tan extraño como un Picasso o un Cézanne. La misma estupefacción les producía Velázquez que Gauguin. Sólo uno de los cuadros que llevábamos les rozaba más de cerca, lo sentían más próximo: una tabla pintada por Berruguete. Y se comprende, porque a estos campesinos, a esos hombres rurales se les había dejado tan hundidos en una fecha remota que aquella tabla del siglo XV parecían reconocerla. ${ }^{5}$

Las Misiones Pedagógicas no llevaban arte para las masas, o para el público, sino para el pueblo, para aquella "inmensa minoría" a la que Juan Ramón Jiménez dedicaba sus escritos. Pintar, escribir, componer, actuar de verdad significaba - para el joven Gaya- hacer algo como "tan sólo se pinta o escribe para el pueblo, para el hombre", hecho que, de por sí, no implica que el pueblo lo aprecie. El arte -añadía- en esto se parece al amor: "es goce y no diversión, enseñanza y no propaganda, dificultad y no facilidad", desgaste y fatiga no siempre comprendida y compartida.

Para entender el compromiso de Gaya para la República tampoco hay que olvidar que sus viñetas estuvieron enriqueciendo las páginas y las portadas de la revista valenciana Hora de España, tal como recuerda María Zambrano al

de las Misiones Pedagógicas y director del Teatro Guiñol, para el cual escribió varias obras, además de haber sido cofundador de la revista Hora de España y colaborador de revistas como El Mono Azul y Romancero General de la Guerra de España. Como muchos otros españoles, se vio obligado al exilio, que transcurrirá -tras un primer momento de reclusión en un campo de concentración francés- entre Argentina, Cambridge y México, para regresar definitivamente a España en 1961.

${ }^{4}$ E. Otero Urtaza, "Entrevista con Rafael Dieste", en Educación y Biblioteca, núm. 119, 2001, p. 28.

${ }^{5}$ Ramón Gaya, España, toreadores, Picasso, en Obra completa. Ed. de Nigel Dennis e Isabel Verdejo, pról. de Tomás Segovia. Valencia/Madrid, Pre-Textos, 2010, p. 318. Berruguete fue un pintor español (ca. 1450-1505) situado en la transición del estilo gótico a la pintura renacentista. Es conocido también como "Pietro spagnuolo", por haber estado en la corte de Federico de Montefeltro en la ciudad italiana de Urbino. El cuadro al cual se refiere Gaya es Auto de fe presidido por santo Domingo de Guzmán. 
escribir de aquel número XXIII - correspondiente a noviembre de 1938, pero que vio la luz muchos años después:

Las viñetas de Ramón Gaya se acuerdan con este lujo de la forma mantenida hasta el instante final por obra de inspiración. De esa inspiración que proviene del acuerdo con la realidad. En la portada interna, una criatura, un muchacho quizás, que se lleva a la boca una cuchara con algo, algo parecido a una sopa tibia, había de ser, con gesto de religiosa unción, casi como si fuera un sacramento. Una mujer en la portada externa, una mujer, la de siempre, la que desde siempre guarda sus lágrimas y con ella intacto el tesoro confiado a la madre, a la hermana, a la hija, a la mujer, alza el brazo y dice adiós con la mano a alguien invisible que se va. Como todos los dibujos de Gaya, que, desde un principio han acompañado Hora de España, aparecen en un aire puro $y$, si es de un interior, con una ventana abierta; circula el aire como en una tragedia, o más bien, misterio, entre cielo y tierra en que la intimidad no deja de serlo por aparecer a la luz. Y el secreto último de esos rostros, de esas cabezas heridas de muerte, de esos brazos que se abrazan a un fusil, de los árboles mismos que cobijan y señalan el lugar del hombre, de los caminos, no se publica ni se diluye. El secreto y la luz que lo descubre se conjugan. Es la libertad. ${ }^{6}$

Su participación a favor de la causa republicana costará a Gaya el exilio: sale de España en 1939, para después viajar rumbo a México a bordo del barco Sinaia. No llegará a integrarse en México y, tras una primera vuelta a Europa en 1952, decidirá establecerse en Roma, yendo y viniendo de España a partir de 1960 y hasta su muerte, en 2005.

Desde México, en 1955, Gaya escribirá un texto conmovedor acerca del Museo del Prado, revelador de su visión del arte, de la pintura y de la herencia de la experiencia republicana:

Cuando pienso en el Prado, éste no se me presenta nunca como un museo, sino como una especie de patria. Hay allí algo muy fijo, invulnerable y también sin remedio, sin redención. Para los franceses, El Louvre no puede ser sino un museo, un museo que está en Francia, pero que, claro, no es Francia. Los museos de Italia siguen siendo exterior, calle italiana, y no hay diferencia entre una sala de los Uffizi y el Arno; todo es igualmente navegable, vivible. Pero el Prado es un lugar hermético, secreto, conventual, en donde lo español va metiéndose en clausura,

${ }^{6}$ María Zambrano, "Hora de España XXIII", en Obras completas VI, pp. 537-538. 
espesándose, encastillándose. Y no es que sólo guarde pintura española, pero allí dentro todo parece convertirse en una misma tierra, en una misma terquedad. La pintura española (Berruguete, Ribera, Zurbarán, Velázquez, Murillo y Goya) no puede, ni con mucho, presentar un índice como puede presentarlo la poesía española [...] y, sin embargo, sentimos que la pintura es nuestro suelo, casi nuestra seguridad. Hay en todo lo español una especie de hambre que en la pintura es donde parece quedar más satisfecha. Si España no hubiese pintado -como no han pintado Alemania, Inglaterra ni Francia-, España sería un país más hambriento, más frenético, más absurdo, más loco; el sentimiento plástico le ha dado a España como una cordura pesante, contrapesante. [...] la pintura es suelo firme, cuerpo, carne, es decir, realidad. ${ }^{7}$

La pintura es, para Gaya, patria y suelo firme para los españoles. La pintura española, añade, "es real como no ha podido serlo nunca la realidad misma española", 8 porque brota de la vida real, desnuda, y no del juego imaginativo; además, lo hace no para emular la realidad, sino para salvarla. Por eso afirma que el Prado le parece como un "manicomio al revés, como un manicomio de cordura, de realidad, de certidumbre":

Afuera está la realidad ilusoria, la vida sueño; pero el arte, para el español es, precisamente, despertar. [...] El arte español es siempre un despertar, una vigilia, una sabiduría última. [...] Cuando pienso en este recinto español no se me presenta nunca como un museo - puesto que no se trata aquí de una simple colección de objetos artísticos-, sino como una roca viva. ${ }^{9}$

Llevar las reproducciones de los cuadros del Prado, "roca viva", a las aldeas españolas, significaba entonces llevar allí tierra firme, una patria común en la cual reconocerse y despertar.

Siempre desde México, Gaya escribirá la mayor parte de los textos reunidos bajo el título Milagro español y pensados para el calendario de 1953. En el primero de ellos leemos:

El genio, en España, no parece tener continuidad. En todo lo español decisivo encontraremos esa condición dura, inhóspita, de lo irrepetible; es más bien como un defecto del genio español, casi una impotencia,

${ }^{7}$ R. Gaya, Recinto español, en Obra completa, p. 837.

${ }^{8}$ Ibid., p. 838.

${ }^{9}$ Ibid., pp. 838-839. 
una imposibilidad de sucederse. El genio italiano, o el alemán, o el francés, se pueden recorrer con muy pocas dificultades; son, cada uno de ellos, una sola línea continuada, correlativa, histórica. El genio español, en cambio, no parece ser una línea, sino unos puntos, unos puntos que no llegan a formar línea alguna, brotados aquí o allá, saltados, rotos, caprichosos. De ese capricho, de esa suerte caprichosa es, quizá, de lo único que está seguro el español; por eso confía, es decir, cree, y apenas es otra cosa que creencia. El español es, principalmente, creencia, no tiene más remedio que ser creencia, porque casi no dispone de nada más; está como desamparado de todo, como huérfano de todo, y siente, sin duda, que su única posibilidad es el genio, o sea, algo grandioso, demasiado grandioso, pero que a él le parece posible, incluso familiar, por ese carácter anárquico, destartalado, sin ley, que suele tener el genio, y que lo hace más asequible, para el español, que el simple talento, ya que el talento se le parece como algo relamido, de academia, de una dificultad despreciable. De ahí que la genialidad no la entienda el español como una categoría máxima, sino como un recurso desesperado. El español que conoce su pobreza y su desorden, parece como si, a falta de otra cosa, se conformase, se aviniese a la genialidad que, muchas veces, no lleva dentro genio alguno y, claro, es entonces una locura. ${ }^{10}$

A la idea de "genio", fruto de la discontinuidad, de la irrepetibilidad, de una grandiosidad que casi culmina en la impotencia y resulta ser un recurso desesperado, Ramón Gaya prefiere la idea de "milagroso". Si el genio, escribe, "es una especie de carácter en acción", de manera diferente "lo milagroso se revela siempre después de lo genial, más allá de lo genial, cuando ya no hay acción ninguna, sino vida". ${ }^{11}$ Lo milagroso, pues, se muestra sin necesidad de demostrarse.

Para mejor entender este lúcido análisis de Gaya acerca del "genio" y del "milagro" -y cotejarlo más adelante con la propuesta de Ernesto Giménez Caballero- hay que remontar a la etimología de los dos términos. Genio deriva del latín genius, vocablo que designaba la guía tutelar o la deidad de un varón, de una familia o de un lugar. Ya en la época de Augusto adquiere su significado secundario de "inspiración", "talento", y conocidas son las reflexiones filosófi-

${ }^{10}$ Este texto, escrito por Gaya en México en 1953, forma parte de Milagro español, título bajo el cual quedan agrupados una serie de textos que giran en torno a las diversas modalidades del "milagro" español. (R. Gaya, Milagro español, en Obra completa, p. 143).

${ }^{11}$ Ibid., p. 179. 
cas que, a lo largo de los siglos, se han desarrollado acerca de la idea de "genio" artístico: las de Hume, Kant, Schopenhauer, Kierkegaard, Nietzsche, etcétera. Diversamente, el término milagro deriva del latín miraculum (maravilla) y suele referirse a un hecho o cosa fuera de lo común, que se considera humanamente imposible. Podríamos decir que si el "genio" nace con la persona y se manifiesta como algo peculiar de ella, que la acompaña o guía, el milagro es, por el contrario, algo aparentemente "independiente" de la persona, de su actividad, de su obrar: algo que acontece. Desde esta perspectiva, es significativo que Gaya hable de "milagro" en relación con el arte español y eso se debe a su peculiar visión del arte y de su relación con la realidad.

El arte, según Gaya, tiene que ver con la vida, con su desnudez. En realidad, escribe en El sentimiento de la pintura, "a una obra de arte no se le puede poner cosas encima ni dentro; no se le puede prestar nada, dar nada desde fuera. El arte no es vestir, sino desnudar". ${ }^{12}$ Justo por esto, nunca puede ser un fin en sí mismo, sino un medio de manifestación de la vida. El arte es, según el pintor murciano, una "concavidad". ${ }^{13}$ Las obras de arte no son propiamente "obras", sino cuevas, nidos, en las que la realidad se refugia y a la par se muestra: "milagros".

Milagros españoles, cóncavos, son, para Gaya, Galdós y su personaje Fortunata, la bailarina Pastora Imperio, Manolete, Picasso, José Bergamín, Luis Cernuda, Juan Guerrero, los músicos Victoria de los Ángeles y Manuel de Falla, Eduardo Rosales, Don Quijote, José Gutiérrez Solana, Zurbarán e Isabel la Católica. Son milagros de la pintura, de la literatura, de la poesía, de la música y hasta de la política.

Se trata de "milagros" (no todo arte es milagroso) por su relación con la realidad: cóncava, piadosa, cuerda, materna. Me centraré en algunos de ellos, literarios y pictóricos: Galdós, Don Quijote, Picasso, Solana y Zurbarán.

El secreto del milagro galdosiano consiste en

[...] tratar a la realidad como a una igual suya, es decir, sin servilismo ni altanería y, claro, sin objetividad, sin el insulto de la objetividad. Los sucesos más sorprendentes, más monstruosos, más inverosímiles, los ve Galdós con una gran naturalidad porque, en vez de mantenerse en esa actitud grosera del que asiste a un espectáculo, se presta delicadamente a ser un amigo de esos sucesos - no a tomar parte, partido en ellos, ya que eso sería meterse donde no le llaman-, se presta, sencillamente, a ser un semejante de la realidad para que ésta no pueda sentirse abandonada ni observada; Galdós no es que se mezcle y se pierda en lo real,

\footnotetext{
${ }^{12}$ R. Gaya, El sentimiento de la pintura, en Obra completa, p. 79.
}

${ }^{13}$ Ibid., p. 60. 
sino que se solidariza con la realidad sin inmiscuirse con ella, y una vez solidarizado, hermanado, nada de esa realidad pudo extrañarle. ${ }^{14}$

Frente a las dos actitudes de los grandes novelistas - "la del impertinente objetivo" de Stendhal y "la del generoso náufrago" de Dostoievski-, la de Galdós se configura como "piadosa" ${ }^{15}$ Su grandeza, su milagro, consiste en "la relación armoniosa que ha quedado establecida, milagrosamente, entre él y la Realidad". ${ }^{16}$ De tal manera que sus personajes, como Fortunata, no vienen como personajes, sino como personas reales, "seres de una robustez única" que no buscan la delgadez del espíritu en un aire favorable, sino que parecen bajar "al fondo de la mina para extraerlo como un carbón". ${ }^{17}$

Entre estos seres "robustos" Gaya incluye también a Don Quijote, entablando un diálogo crítico con la interpretación de Thomas Mann. Sabido es que el escritor alemán retomó la lectura de la obra de Cervantes en el barco que en mayo de 1934 le estaba llevando al exilio: un libro, según escribe en su diario de a bordo, "de un pueblo y de la humanidad entera", ${ }^{18}$ una obra que "estaba concebida como broma modesta, satírica, grosera", sin que su creador sospechara "el rango de símbolo humano que adoptaría más tarde el héroe". ${ }^{19}$ Cabe destacar que Don Quijote ha sido una figura retomada por muchos exiliados y que el desajuste entre sus sueños, sus proyectos y su vocación de justicia con respecto a la realidad ha sido tema constante también de la literatura y del pensamiento del exilio español de $1939 .^{20}$ Sin embargo, Gaya no comparte las conclusiones de Thomas Mann cuando anotaba que el hidalgo "es un loco, pero en manera alguna es tonto; esto no lo ha sabido el autor de antemano", ${ }^{21}$ sino que lo han descubierto sus lectores. Y Sancho, escudero fiel del hidalgo, representaba para Mann la inquietante "relación del pueblo español con la noble locura que está llamado a servir mal o bien":

${ }^{14}$ R. Gaya, "Galdós", en Milagro español, p. 144.

${ }^{15}$ Ibid., pp. 144-145.

${ }^{16}$ Idem.

${ }^{17}$ R. Gaya, "Fortunata", en Milagro español, p. 151.

${ }^{18}$ Thomas Mann, "A bordo con don Quijote", en Cervantes, Goethe, Freud. Pról. de Guillermo de Torre. Buenos Aires, Losada, 1961, p. 28.

${ }^{19}$ Ibid., p. 38.

${ }^{20}$ Véase J. L. Mora García, "Lecturas del Quijote en el exilio", en A. Sánchez Cuervo y F. Hermida de Blas, coords., Pensamiento exiliado español. El legado filosófico del 39 y su dimensión iberoamericana. Madrid, Biblioteca Nueva/CSIC, 2010, pp. 164202; Elena Trapanese, "El caballero de la locura y su ambigüedad: don Quijote entre Unamuno y Zambrano”, en Bajo Palabra. Revista de Filosofía, 2a. época, núm. 5, 2010, pp. 349-366.

${ }^{21}$ Th. Mann, "A bordo con don Quijote", en op. cit., p. 38. 
Ya desde ayer me preocupa esto. He aquí una nación que realiza en su libro-tipo y reconoce con orgulloso y severo dolor la melancólica burla y la reducción ad absurdum de sus calidades clásicas: grandeza, idealismo, generosidad mal aplicada, caballerosidad inútil. ¿No es extraño esto? La grandeza histórica de España está situada en siglos lejanos; en el nuestro tiene que luchar con dificultades de adaptación. [...] La historia es la realidad corriente para la que hay que haber nacido y ser apto y en la que fracasa la nobleza inadaptada de don Quijote. ${ }^{22}$

Mann se lamentaba de la cordura final del hidalgo, como si se tratara de un fracaso e interpretaba su muerte como una medida de precaución amañada y demasiado literaria, ${ }^{23}$ tomada por Cervantes por celos hacia su personaje: "nos da lástima Don Quijote”, escribía, pues la razón de su muerte ha de buscarse en la depresión producida por "el fracaso de su misión vital como caballero andante y paladín del derecho". ${ }^{24}$ El escritor alemán no entendió -comenta Gaya-que se trataba de un "fenómeno de exclusividad española", porque solo un español "puede volverse cuerdo". ${ }^{25}$

Alonso Quijano no es, como se sabe, un loco, sino un cuerdo, pero es un cuerdo incompleto, que necesita lograrse, merecerse, someterse a prueba, renacer. Junto a la cordura grande, alta, sufrida, de don Quijote en su lecho de muerte, la cordura de los demás resulta baja, corta; y lo que no comprende Thomas Mann es eso: que la cordura última de don Quijote no es ya la misma de antes, no es ya la cordura virgen, tonta, vacía de antes, sino una cordura luminosa, iluminada, ganada, rica, total. Alonso Quijano atraviesa la locura como atraviesa Velázquez la realidad; uno y otro comprenden -o sienten- que realidad y locura no tienen que ser evitadas, sino vencidas, vencidas hasta lo último, apuradas como un cáliz. ${ }^{26}$

El español, apunta Gaya, llega a lo último tropenzando con las cosas inmediatas. Un tropezar, el de Don Quijote, que no humilla lo inmediato, sino que revela su carácter transitorio:

22 Ibid., pp. 29-30.

23 "Es el tránsito sensato y tranquilo de un hombre bueno, digno y cristiano, después de haberse confesado y confortado espiritualmente y de haber dejado en orden, con ayuda del escribano, sus asuntos temporales" (ibid., p. 65).

${ }^{24}$ Ibid., p. 64.

${ }^{25}$ R. Gaya, "Don Quijote", en Milagro español, p. 173.

${ }^{26}$ Idem. 
Don Quijote no es, quizá, el nombre de una persona, sino el nombre de un sitio, de un lugar que todos llevamos, que todos deberíamos extraer de nosotros y extender ante nosotros para que pudiera ser cruzado, para que pudiera ser pisado; un lugar que podría llamarse también purgatorio, que no es un lugar de estar, de quedarse, sino de ir de paso, de ir de vuelo. Don Quijote tiene, en su lecho de muerte, unos instantes de totalidad, de [...] satisfacción; la satisfacción de la realidad cumplida. ${ }^{27}$

El libro de Cervantes, escribe Gaya en El sentimiento de la pintura, "ni siquiera es un libro", sino que es "algo así como un gran portalón abierto de par en par [...] al vacío, región difícil para el hombre". ${ }^{28}$ Como todo milagro artístico, Don Quijote se le escapa a Cervantes, como saliendo de una prisión hacia la libertad, pero sólo gracias al gesto de "generosidad infinita" del artista por mantener ese vacío, esa concavidad propia de todo arte verdadero. Ésta es la razón por la cual nos parece tan impresionante el final, "cuando vemos que don Quijote no es, como creen algunos, que gane la razón, sino que pierde la locura". 29

A Galdós, Fortunata y Cervantes se suman como milagros españoles, en ámbito pictórico, además que el tan amado Velázquez, Picasso, Solana, Zurbarán. Milagros a veces no entendidos, no reconocidos o mal entendidos por la crítica.

José Gutiérrez Solana, desde el "desaliño" y la "mala factura" 30 de sus telas, nos muestra la vida en su mezcla de miseria y generosidad. Si sus cuadros disgustan es porque no entendemos nada de la vida, de lo real vivo: el arte verdadero, cóncavo, no admite "retoques" de la realidad, porque la realidad viva

[...] no tiene defectos, no puede tener defectos porque ella no es obra, no es una obra... puesta a juicio; lo que puede juzgarse es todo aquello que ha sido hecho, pero no lo que ha sido nacido (de ahí que la crítica de arte sea un absurdo y un imposible, porque el arte, como se sabe, no pertenece a la especie de las cosas hechas, sino nacidas) [...]. Solana es como una novela de Galdós de la que se han perdido o traspapelado páginas y nada concuerda ya, en donde los hechos no coinciden, no coinciden pero existen. ${ }^{31}$

Lo milagroso de Zurbarán consistió en la brillantez de su modestia: se trata de "un pintor pueblerino, pobre de recursos", que "iba pintando sus famosos

${ }^{27}$ Ibid., pp. 174-175.

${ }^{28}$ R. Gaya, El sentimiento de la pintura, en op. cit., p. 64.

${ }^{29}$ Ibid., p. 65.

${ }^{30}$ R. Gaya, "José Gutiérrez Solana", en Milagro español, p. 175.

${ }^{31}$ Ibid., pp. 175-176. 
monjes sin modelo vivo y, los ropajes, puestos en una especie de espantapájaros, los iba llenando, milagrosamente, de persona". ${ }^{32}$ Zurbarán, comenta Gaya, actuaba como "con una especie de timidez ante la realidad", tomándola en cuenta sin por eso adularla. Lo milagroso de su pintura ha consistido en haber logrado invitarnos a un festín de "pobreza", de "Modestia" 33 frente a la realidad, de concavidad.

Entre los grandes milagros españoles encontramos también a Velázquez: creador y no mero artista, el pintor sevillano no pinta obras maestras, sino que crea seres vivos, hijos vivos. La mano milagrosa de Velázquez consigue liberar la realidad, sin fijarla. La realidad, escribe Gaya, nunca aparece "violentada" como hace cierto arte realista, sino que "aparece siempre yéndose; yéndose por el fondo, por la puerta del fondo, una puerta que, a veces, como sucede en Las Meninas, es visible, y otras no, pero siempre practicable". La realidad en los lienzos de Velázquez, no llega nunca a ser "argumento", sino que se muestra como una cortina (de humo, húmeda) "que no podemos descorrer ni evitar a la torera -como demasiado alegremente intenta el arte, el arte artístico- sino algo que debemos aceptar y trascender". La mano milagrosa de Velázquez consigue vaciar la realidad sin alterarla, transcenderla hacia un centro de luz escondida, pero resistente. El milagro consiste, justamente, en dejar ver esta luz sin descorrer la cortina, sino abrazándola.

El arte creación de Velázquez es, desde este punto de vista, un milagro español "muy poco español": El arte español, lo español en suma, es como si tuviera no ya el atrevimiento y el descaro de existir -según vemos en lo italiano-, sino el desprecio y la arrogancia de existir. El realismo español, o cierto realismo español, no adhiera a la realidad, sino que parece oponerse a ella oponiéndole no "la fantasía, ni la imaginación, ni el sueño", sino que "más realidad, una mayor, más feroz, más frenética” realidad.

"Milagros" por haber ido más allá del genio, por haber cedido a la realidad sin caer en la tentación de actuar sobre ella, de retocarla o llenarla desde fuera. Milagros españoles. Milagros por haber ido más allá de la cerrazón que, según Gaya, caracteriza a lo español. "España: milagro y cerrazón", ya que en España "lo que no es genialidad milagrosa, es cerrazón irredenta. No hay otras posibilidades".

Estas reflexiones resultan aún más interesantes si las cotejamos con el uso de los términos "genio" y pueblo que, en la España de los años treinta, había hecho Ernesto Giménez Caballero en su libro Genio de España, que, publicado por primera vez en 1932, llegó a su sexta edición en 1939.

32 R. Gaya, "Zurbarán”, en Milagro español, p. 107.

${ }^{33}$ Idem. 
Un libro escrito, según nos dice el autor, en tiempos "herejes, demoníacos, liberales" ${ }^{34}$ de la historia de España, para que lo leyeran las almas "genuinas" 35 y en abierta contraposición con Miguel de Unamuno, la generación del 98 y José Ortega y Gasset (criticando la idea orteguiana de generación y sustituyendo a ella la de ciclo espiritual, Giménez Caballero afirmaba no poder sentirse solidario "de gentes de mi generación que luchan contra mi causa desde la otra trinchera. Con el comunismo, la democracia, el intelectualismo y el Frente Popular, yo no tengo raíz alguna de mi ser que participe"). ${ }^{36}$ Un libro que, según Giménez Caballero, tomaba su sustancia en "el pueblo, el genio de España", ${ }^{37}$ para el escritor fascista "encarnación de Israel y de Roma": "Lo importante es marchar. Lo importante es despertarse. Lo importante es que un pueblo sienta su propia genialidad y, como sobre un río majestuoso, bogue en la barca, oportuna, que le ofrezca cualquier humilde y modesto braguero [imodesto hasta el punto de autodefinirse poeta y profeta de la patria!]"

Genio es, desde el punto de vista etimológico, "la fuerza genesíaca, creadora, vital en función inmanente. El modo específico de manifestarse la Vida, la Divinidad, en un Tiempo y Espacio determinados". ${ }^{38}$ Cada lugar, entonces, tendría su genio, su íntimo secreto vital. El escritor franquista, quien no duda en definirse poeta y profeta del genio español, identifica tres "genios» fundamentales del mundo que, como nubes en el cielo, son siempre 'iguales', tornan y retornan como "batallas y tormentas": 39 el genio de Oriente (la dependencia del hombre de Dios), el Genio de Occidente (la independencia del hombre respecto a Dios) y el Genio de Cristo (genio mediador entre Oriente y Occidente), del que cree que el genio de España sea fiel heredero a través de la Roma imperial y fascista. Carácter genial y genético, el genio de España es "universo", católico e imperial, por dar a César lo que es de César y a Dios lo que es de Dios. ${ }^{40}$ A este concepto, el autor opone el de "bastardía" espiritual: bastardos espirituales fueron, para Giménez Caballero, "todos los heterodoxos españoles de tres siglos": hijos "de dos madres", 41 "98 espirituales" y fautores de la decadencia de España ya desde la época de Cervantes por no aceptar el autoritarismo del genio español y por no entender que los muertos son "lo más vivo que el genio de una patria tiene". ${ }^{42}$ Don Quijote, lejos de ser un "milagro"

${ }^{34}$ E. Giménez Caballero, Genio de España. Exaltaciones a una resurrección nacional y del mundo (1932). Pról. de F. Sánchez Dragó. Barcelona, Planeta 1983, p. 8.

${ }^{35}$ Ibid., p. 12.

${ }^{36}$ Ibid., p. 20.

${ }^{37}$ Ibid., p. 13.

${ }^{38}$ Ibid., p. 142.

${ }^{39}$ Ibid., p. 202.

${ }^{40}$ Ibid., p. 203.

${ }^{41}$ Ibid., p. 79.

${ }^{42}$ Ibid., p. 121. 
español, es un peligro: su duplicidad, su grandeza e infamia, su bastardía consiste en el hecho de haber dado voz a la "inquietud", así rompiendo su "nervatura a la humanidad moderna". ${ }^{43}$ Es evidente que, cuando el mundo se polariza entre "bastardos" y "geniales", no queda nada más que la violencia, la guerra, la lógica de la enemistad.

Frente a una tal retórica de la muerte, de la acción y del autoritarismo, que sin duda Gaya tuvo que conocer durante la guerra civil, resulta de gran interés la que podríamos definir su "contrapropuesta artística": la de una España cóncava, una patria pictórica y literaria a la que los exiliados dieron voz y forma en sus obras, llevándola consigo en el recuerdo. La canción y el pincel se fueron al destierro:

Franco, tuya es la hacienda,

la casa,

el caballo

y la pistola.

Mía es la voz antigua de la tierra.

Tú te quedas con todo y me dejas desnudo y errante por el mundo...

Mas yo te dejo mudo..., imudo!, y ¿̇cómo vas a recoger el trigo

y a alimentar el fuego

si yo me llevo la canción? ${ }^{44}$

${ }^{43} \mathrm{Ibid}$., p. 80.

${ }^{44}$ León Felipe, Nueva antología rota. Madrid, Akal, 2008, p. 177. 